\title{
Intracranial pressure pulse amplitude during changes in head elevation: a new parameter for determining optimum cerebral perfusion pressure?
}

\author{
Felix Mahfoud • Jürgen Beck • Andreas Raabe
}

Received: 6 April 2009 /Accepted: 9 September 2009/Published online: 6 October 2009

(C) Springer-Verlag 2009

\begin{abstract}
Objective During short-term postural changes, the factors determining the amplitude of intracranial pulse pressure (ICPPA) remain constant, except for cerebrovascular resistance (CVR). Therefore, it may be possible to draw conclusions from the ICPPA onto the cerebrovascular resistance (CVR) and thus the relative change in cerebral perfusion pressure (CPP).

Methods Age, sex, disease, Glasgow Coma Scale score, placement of ventricular drain, blood gas analysis, and parameters of airway management were prospectively recorded in 40 patients. The changes in intracranial pressure (ICP), CPP, mean arterial pressure (MAP), and ICPPA at head elevations of $0^{\circ}, 30^{\circ}$, and $60^{\circ}$ were measured and analyzed online. Status of cerebrovascular autoregulation was checked using the pressure-reactivity index (PRx).

Results Altogether 36 subjects fulfilled the study conditions. Three patients had positive PRx indicating disturbed autoregulation and were excluded. Thus, 33 were left for analysis (18 females and 15 males). All of them were sedated and mechanically ventilated with Glasgow Coma scores ranging from 3-8. During change in head elevation from $0^{\circ}$ to $60^{\circ}$, we found a significant $(\mathrm{p}<0.05)$ improvement of the ICP, an increase of the ICCPA, a reduction of the MAP, and a decrease in the CPP. Increasing ICPPA was linked to decreasing CPP $\left(0^{\circ}\right.$ to $\left.60^{\circ}, \mathrm{r}=-0.42, \mathrm{p}<0.05\right)$.
\end{abstract}

F. Mahfoud $\cdot$ J. Beck $\cdot$ A. Raabe

Department of Neurosurgery, Neurocenter,

Johann Wolfgang Goethe University,

Frankfurt am Main, Germany

F. Mahfoud $(\square) \cdot$ A. Raabe $(\bowtie)$

Department of Neurosurgery, Inselspital,

Freiburgstrasse,

3010 Bern, Switzerland

e-mail: andreas.raabe@insel.ch
Conclusions Head elevation is an important part of the ICP and CPP therapy in neurointensive care. When searching for the patient-specific optimum upper body position, ICPPA may provide additional information. Providing that the cerebral autoregulation is intact, the lowest ICPPA of a patient corresponds to the individual upper body position with the highest CPP.

Keywords Head elevation - Intracranial pressure . Intracranial pulse wave amplitude .

Cerebral perfusion pressure - Neurointensive care .

Cerebrovascular autoregulation

\section{Introduction}

Continuous monitoring of intracranial pressure (ICP) is widely used in neurointensive care patients to maintain adequate ICP and cerebral perfusion pressure (CPP) levels [7]. The traditional practice of elevating the head in order to lower the ICP has been a matter of debate for years. This maneuver often only focuses on ICP and does not take into consideration the decrease in arterial blood pressure (ABP) that also occurs at the level of cerebral circulation when the head is elevated. Therefore, either direct measurement of CPP or indirect assessment of CPP during positional changes is required to find the optimum CPP-position for an individual patient.

ICP pulse amplitude (ICPPA) can be easily assessed using ICP monitoring. Physiologically, ICPPA is composed of (1) the magnitude of the pulsatile changes in cerebral blood volume and (2) the volume reserve or craniospinal compliance [4-6, 9]. According to Avezaat and van Eijndhoven [4-6], the former is determined by the interaction between the pulsatile arterial inflow and venous outflow curves, i.e., by 
the pulsatile volume load of blood to the craniospinal system. Clinically, these are mostly influenced by cardiac factors and cerebral vasomotor tonus.

Provided that under stable clinical conditions the craniospinal compliance and cardiac factors remain constant, a change in ICPPA would indicate a change in the cerebrovascular resistance (CVR) that is triggered by an increase or decrease in CPP during a change in head elevation.

Therefore, the aim of this prospective study was to investigate possible relationships among ICP, CPP, and ICPPA during changes in body position. Specifically, we sought to investigate (1) whether there is a relationship between ICPPA and CPP during head elevation, and (2) whether ICPPA can be used as a simple qualitative surrogate parameter to determine the optimal upper body position with the optimum CPP in neuro intensive care patients with ICP monitoring.

\section{Clinical material and methods}

The study included 33 adults admitted to the Neurocritical Care Unit, Department of Neurosurgery, Johann Wolfgang Goethe University, Frankfurt am Main, Germany. The ethics committee of the University of Frankfurt am Main approved the study protocol.

\section{Patient population}

Between January 2005 and January 2006, 33 patients with preserved cerebrovascular autoregulation were analyzed. There were 18 females (55\%) and 15 males (45\%). Age ranged from 16 to 84 years (mean 54 years). The primary diagnosis was subarachnoid hemorrhage (SAH) in 15 patients, intracerebral hemorrhage (ICH) in 6 , a combination of SAH and ICH in 3, epidural hematoma in 2, head injury in 2 , brain tumor in 2 , subdural hematoma in 2 , and stroke in 1 patient. Further demographic characteristics of the patients are given in Table 1 and the absolute values of ICP, ICPPA, CPP, and MAP in relation to head elevation in Table 2. Table 3 shows the relative changes in values of various parameters from $0^{\circ}$ to $30^{\circ}, 30^{\circ}$ to $60^{\circ}$, and $0^{\circ}$ to $60^{\circ}$ of head elevation.

All patients were sedated, mechanically ventilated, and treated following standards for advanced trauma life support and common guidelines [7]. The treatment protocol was based on maintaining the CPP $>60 \mathrm{mmHg}$, controlling intracranial hypertension (ICP $<20 \mathrm{mmHg}$ ), and maintaining euvolemia, euglycemia, and normothermia. Barbiturates were not applied.

Cerebral autoregulation was tested using the pressurereactivity index (PRx) of Czosnyka et al. [10], which is
Table 1 Characteristics patients*

\begin{tabular}{ll}
\hline Sex (M:F) & $18: 15$ \\
Age range (mean) & $16-84(54)$ \\
Underlying disease & \\
Subarachnoid hemorrhage (SAH) & 15 \\
Intracerebral hemorrhage (ICB) & 6 \\
Combination SAH and ICB & 3 \\
Subdural hematoma & 2 \\
Epidural hematoma & 2 \\
Head injury & 2 \\
Brain tumor & 2 \\
Stroke & 1 \\
PEEP (mbar) & $6.8 \pm 0.3$ \\
paO & (mmHg) \\
paCO & (mmHg) \\
pH $_{\text {Intraventricular probe }}$ & $125.34 \pm 4.8$ \\
Intraparenchymal probe & $34.67 \pm 0.84$ \\
\hline
\end{tabular}

*Values represent mean \pm standard error of the mean (SEM)

a calculation of the correlation coefficient between MAP and ICP. Only patients with intact autoregulation reflected by a negative value of PRx were included in our study.

At the time of measurement, all patients were in stable hemodynamic conditions. No changes in drug therapy or respiratory management were made for $30 \mathrm{~min}$ before the study or during the period of study.

Data acquisition and analysis

ICP was monitored with intraparenchymal (3PN, Spiegelberg $\mathrm{GmbH}$, Hamburg, Germany) or intraventricular probes (Codman Microsensor, Johnson\&Johnson, Raynham, MA).

Mean arterial blood pressure (MAP) was measured invasively via an arterial cannula (Arteriofix art.-Kath.-Set 22G, B.Braun, Melsungen, Germany) positioned in the radial artery and connected to a pressure transducer.

Real-time analog signals from ICP, ICPPA, CPP, and MAP were collected, averaged every second, and digitized using an AD converter card (DC DT-300, Data Translation, Marlboro, MA). Multimodal monitoring software (BioSAn, Biological Signal Analyzer, P. Smielewski, M. Czosnyka, Cambridge, UK) was used for data storage and online or offline analysis (time resolution $0.5 \mathrm{~Hz}$ ).

All statistical analyses were performed with SPSS (version 11.0, SPSS Inc., Chicago, IL). Collected data were checked for standard normal distribution. A paired t-test was performed. The associations between continuous variables were analyzed using the Pearson correlation (r). Significance (p) was reached at a probability level less than 0.05 . 
Table 2 Absolute values of ICP, ICPPA, CPP, and MAP in relation to head elevation

*Values (in $\mathrm{mmHg}$ ) represent mean \pm SEM

\begin{tabular}{llllll}
\hline & $0^{\circ}$ & $30^{\circ}$ & $60^{\circ}$ & $30^{\circ}$ & $0^{\circ}$ \\
\hline ICP & $20.3 \pm 0.9$ & $13.4 \pm 0.9$ & $11.8 \pm 1.1$ & $13.8 \pm 1.1$ & $21.6 \pm 1.0$ \\
ICPPA & $6.6 \pm 0.5$ & $6.5 \pm 0.4$ & $7.4 \pm 0.5$ & $6.6 \pm 0.4$ & $6.8 \pm 0.4$ \\
CPP & $72.8 \pm 2.2$ & $67.5 \pm 2.0$ & $62.6 \pm 2.1$ & $66.8 \pm 2.2$ & $70.8 \pm 2.2$ \\
MAP & $93.0 \pm 2.4$ & $80.1 \pm 2.2$ & $74.4 \pm 2.3$ & $80.6 \pm 2.4$ & $92.4 \pm 2.5$ \\
\hline
\end{tabular}

\section{Results}

Intracranial pressure and ICP wave amplitude

Before measurement, all patients were positioned $25-30^{\circ}$ head-up with the head in a neutral non-rotated or flexed position with reference to the torso.

Intraventricular cerebrospinal fluid (CSF) drainages were closed. The transducers (MX 960, Medex Medical Ltd., Rossendale, UK) for MAP and ICP were then calibrated to the level of foramen of Monro and connected to the patient monitor (Siemens SC 9000, Dräger Medical Inc., Danvers, MA). Both transducers were fixed at the head of the patient at the level of the foramen of Monro. The influence of the hydrostatic pressure difference while tilting the table was thereby eliminated. Blood was withdrawn from the arterial catheter to measure $\mathrm{paCO}_{2}, \mathrm{paO}_{2}$, and $\mathrm{pH}$ value.

The examination then started by positioning the patients flat $\left(0^{\circ}\right)$. After reaching a steady state for at least $5 \mathrm{~min}$, measurements were taken of the ICP, ICPPA, CPP, and MAP. CPP was calculated as the difference between the measured MAP and ICP. Following each set of measurements, the patient's head was elevated to the next selected position $\left(30^{\circ}, 60^{\circ}\right.$, and again $\left.30^{\circ}, 0^{\circ}\right)$. Again, after reaching a steady state in the new position, the measurements were repeated. The angle of elevation was shown by the digital monitor of the patient's bed (Model S, Völker Inc., Witten, Germany). For each of the patients, the results of the measured parameters recorded for each of head-level elevations were averaged.

An instable ICP or ICP increase above $40 \mathrm{mmHg}$ during $0^{\circ}$ position were used as criteria to abort the study in any given patient.

Table 3 Relative changes in values of various parameters from $0^{\circ}$ to $30^{\circ}, 30^{\circ}$ to $60^{\circ}$, and $0^{\circ}$ to $60^{\circ}$ of head elevation

\begin{tabular}{llll}
\hline Parameter recorded & \multicolumn{3}{l}{ Head elevation } \\
\cline { 2 - 4 } & $0^{\circ}$ to $30^{\circ}$ & $30^{\circ}$ to $60^{\circ}$ & $0^{\circ}$ to $60^{\circ}$ \\
\hline$\Delta$ ICP & $-6.9 \pm 0.5$ & $-1.5 \pm 0.5$ & $-8.5 \pm 0.8$ \\
$\Delta$ ICPPA & $-0.1 \pm 0.2$ & $+0.9 \pm 0.2$ & $+0.8 \pm 0.3$ \\
$\Delta$ CPP & $-5.3 \pm 0.8$ & $-4.9 \pm 1.0$ & $-10.2 \pm 1.3$ \\
$\Delta$ MAP & $-12.1 \pm 0.7$ & $-6.5 \pm 1.0$ & $-18.6 \pm 1.2$ \\
\hline
\end{tabular}

Values (in $\mathrm{mmHg}$ ) are means $\pm \mathrm{SEM} . \mathrm{ICP}=$ intracranial pressure; $\mathrm{ICPPA}=$ intracranial pressure wave amplitude; $\mathrm{CPP}=$ cerebral perfusion pressure; MAP $=$ mean arterial blood pressure
The ICP for all patients increased when the patient was placed at $0^{\circ}$ (Fig. 1). The lowest ICP was found at $60^{\circ}$ head elevation $(11.8 \pm 1.1 \mathrm{mmHg})$ and the highest at $0^{\circ}$ head elevation $(20.3 \pm 0.9 \mathrm{mmHg})$. The mean ICP decreased significantly $(-8.5 \pm 0.8 \mathrm{mmHg}, \mathrm{p}<0.001)$ when the head was elevated from $0^{\circ}$ to $60^{\circ}$.

With elevation of the head, the ICPPA increased significantly $(\mathrm{p}<0.001)$ from $6.5 \pm 0.4 \mathrm{mmHg}$ at $30^{\circ}$ to $7.4 \pm 0.5 \mathrm{mmHg}$ at $60^{\circ}$; mean change was $+0.9 \pm$ $0.2 \mathrm{mmHg}$ (Fig. 2). For most patients, the minimum of the ICPPA was found at $30^{\circ}$ head elevation $(n=16)$. However, in 13 patients the lowest ICPPA and highest CPP were found at the $0^{\circ}$ position. There was no patient with the lowest ICPPA and highest CPP in the $60^{\circ}$ position.

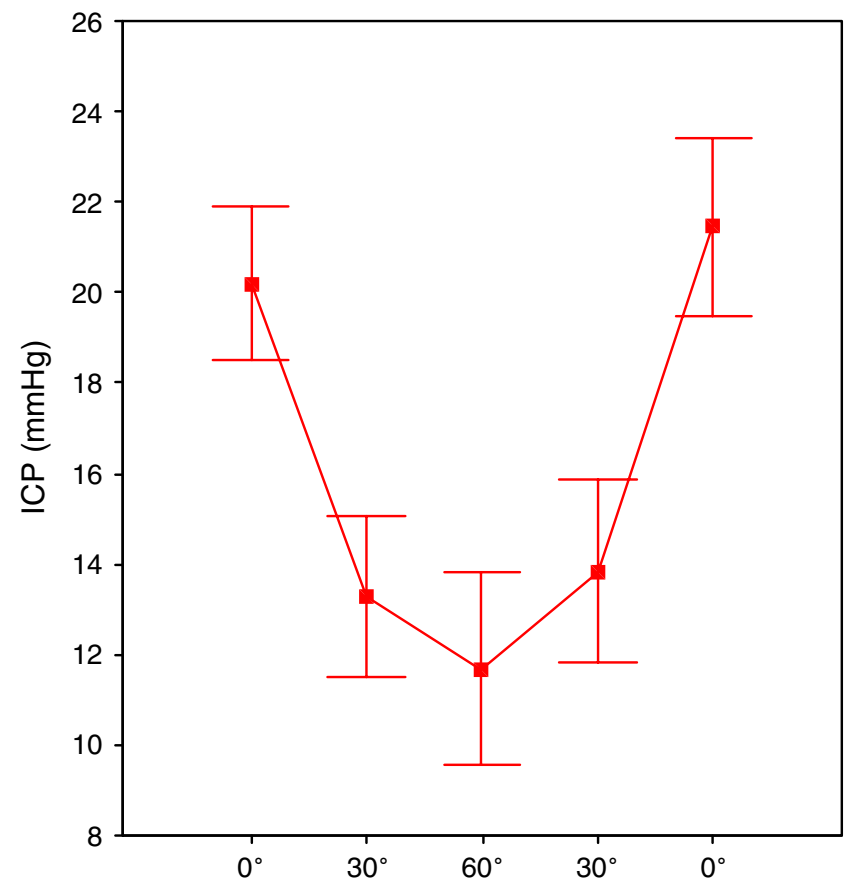

Fig. 1 Mean ICP \pm SEM decreased while moving to $60^{\circ}$ head-up position $(\mathrm{p}<0.05)$ 


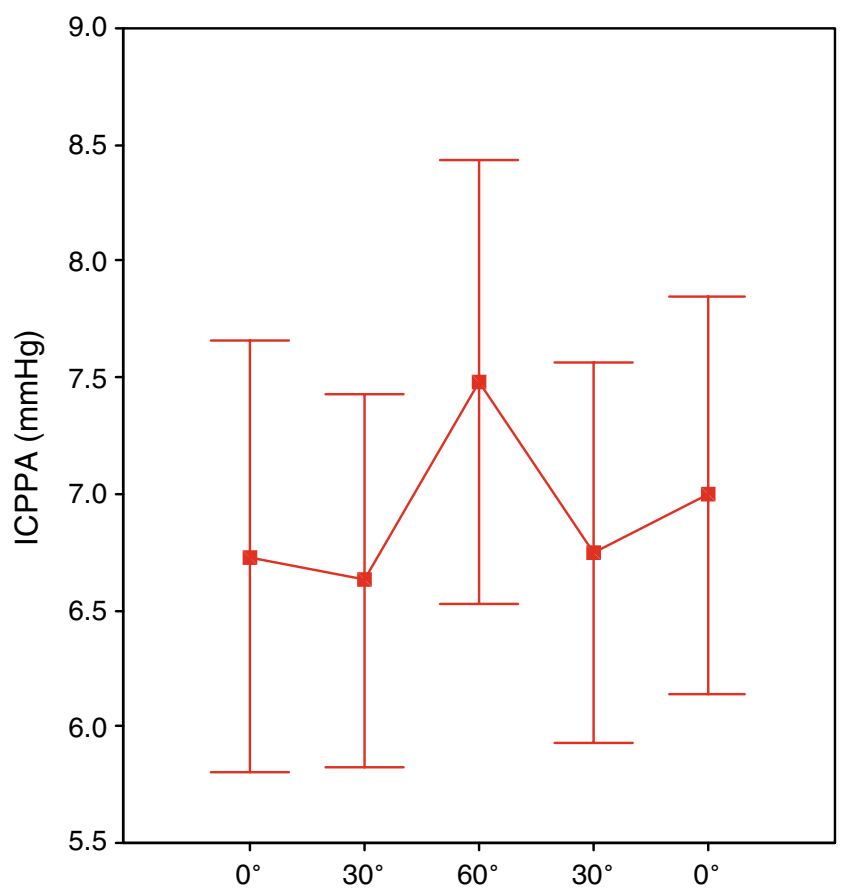

Fig. 2 Mean \pm SEM of measured ICPPA at head elevation. The ICPPA increased at $60^{\circ}$ head-up position $(\mathrm{p}<0.05)$

Mean arterial blood pressure and cerebral perfusion pressure

The mean MAP, recorded at the level of the foramen of Monro, fell with the progressive head elevation. Elevation to $60^{\circ}$ produced a significant decline in both CPP (decrease of $-10.2 \pm 1.3 \mathrm{mmHg}$ ) and MAP (decrease of $-18.6 \pm$ $1.2 \mathrm{mmHg}$ ) when compared to baseline levels (Figs. 3, 4).

A significant linear correlation was noted between the changes from $0^{\circ}$ to $60^{\circ}$ in the ICPPA and CPP $(\mathrm{r}=-0.42$, $\mathrm{p}=0.016)$, ICP and CPP $(\mathrm{r}=-0.5, \mathrm{p}=0.003)$, and MAP and CPP $(r=0.81, p<0.001)$ (Fig. 5). The lower the CPP, the greater the increase in ICPPA, an observation that supports the theory of using ICPPA as a marker for CPP in patients with intact cerebrovascular autoregulation.

Altogether, in four patients the study had to be aborted. In two patients ICP increased $40 \mathrm{mmHg}$ and in two when MAP exceeded $150 \mathrm{mmHg}$ during the change of body position.

\section{Discussion}

Rationale of using ICP pulse amplitude for qualitative assessment of CPP

Cerebral ischemia after brain injury is associated with adverse outcomes and death. It is a vital goal in neurointensive care to maintain adequate cerebral perfusion and

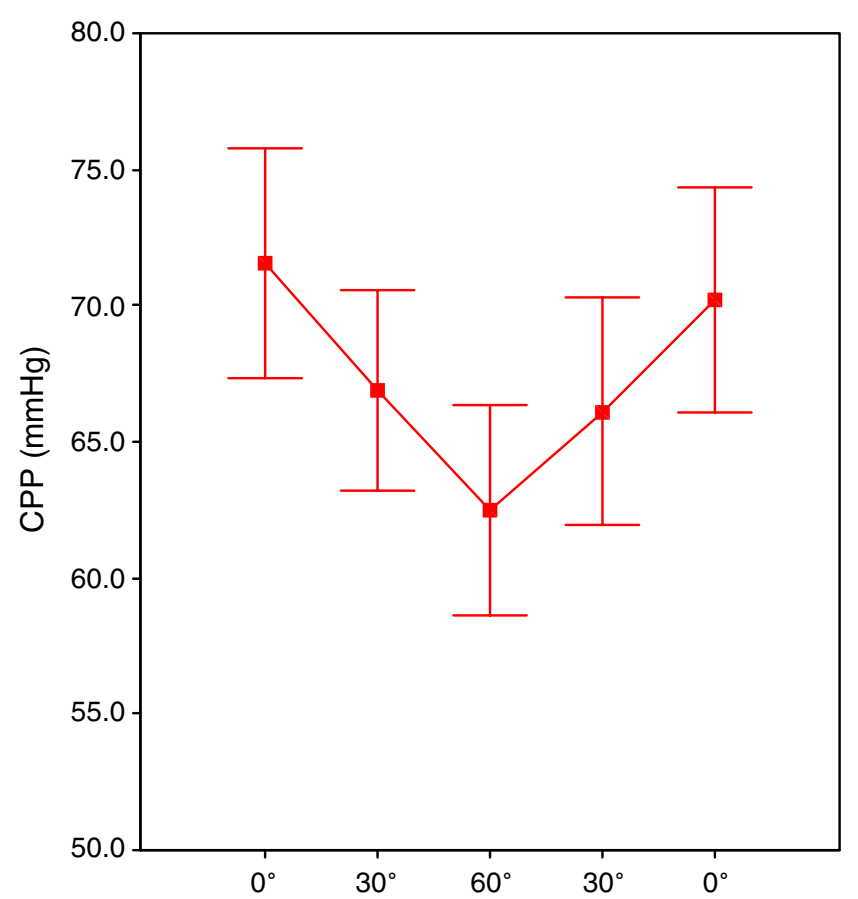

Fig. 3 Decrease in mean CPP \pm SEM while position change was significant $(\mathrm{p}<0.05)$

to prevent episodes of cerebral ischemia. There is wide agreement that CPP represents an important treatment target and that measures should be taken to maintain at least $60 \mathrm{mmHg}$ of mean CPP [9]. Steiner et al. [47] were able to link impaired autoregulation to poor outcome following head-injury, but were unable to correlate CPP value and

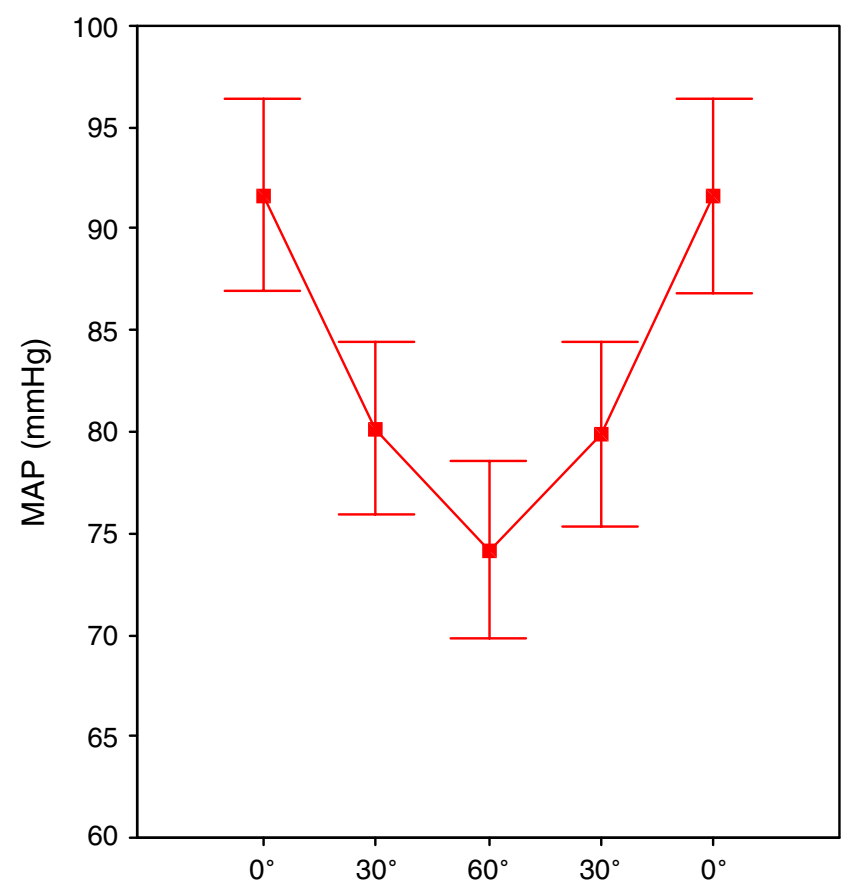

Fig. 4 Mean $\mathrm{MAP} \pm \mathrm{SEM}$ increased while raising the head up $(\mathrm{p}<0.05)$ 
outcome. This is confirmed by the findings of Juul et al. [22]. In the comparison of a CPP- or a ICP-oriented therapy, Robertson et al. [39] showed a decrease in ischemic insult in CPP-oriented therapy, but an increase in respiratory complications with no convincing differences in outcome. There is agreement that body positioning may influence CPP and that it should be individualized for each patient based upon various data [13, 25, 41, 47].

However, the interaction between ICP and MAP at the level of the cerebral circulation during a change of body position is complex, and determining the body position with the optimum CPP in a given patient is not trivial.

Many fundamental studies about the physiology of ICPPA and craniospinal compliance were performed in the 1970s and 1980s. These landmark studies pioneered by Marmarou et al., Miller et al., Avezaat and van Eijndhoven, and others led to an improved understanding of the intracranial pressure-volume relationship. Based upon these data, ICPPA may provide important information about the cerebral vasomotor tonus.

\section{ICP pulse amplitude}

The importance of the intracranial volume-pressure relationship for understanding the pathophysiology of raised ICP and ICPPA has been demonstrated in several studies [4, 27, 28, 30, 32, 43, 49, 51].

The ICPPA increases with rising ICP in accordance with the exponential shape of the craniospinal volume-pressure curve. Avezaat et al. [4] showed that the magnitude of ICPPA is determined by the craniospinal compliance and the amount of pulsatile change in cerebral blood volume. The latter is composed of cardiac stroke volume and the arterial inflow and venous outflow dynamics of the craniospinal compartment. Here, CVR plays a major role for determining the ICPPA $[4,5]$. It is unlikely that the volume compensation reserve or craniospinal compliance changes with increasing or decreasing head elevation. Provided that cardiac parameters such as blood pressure, stroke volume, and heart rate remain constant during a change in head elevation, CVR remains as the single major factor for determining whether ICPPA increases, decreases, or remains stable. This hypothesis is supported by the finding that the decrease in mean ICP during a change in head elevation from $30^{\circ}$ to $60^{\circ}$ is often accompanied by a delayed increase in ICP and a markedly increased ICPPA that cannot be explained by a change of the craniospinal compliance (Figs. 5, 6, 7), but by a response in CVR (vasodilatation) triggered by a decrease in CPP.

Eide et al. [14] investigated how the ICP levels and ICPPA were linked to the acute clinical state and final clinical outcome (Glasgow Outcome Score, GOS). The mean ICPPAs were significantly lower in the category of

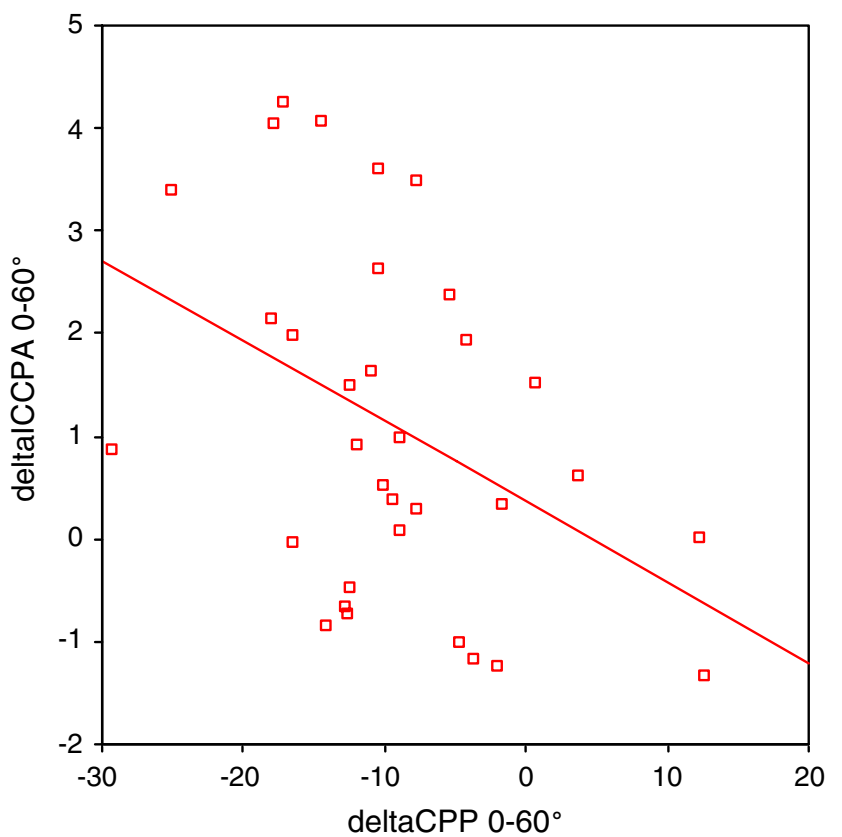

Fig. 5 Relationship between the change in ICPPA and the change in CPP during the various maneuvers of changing head elevation. There is a linear correlation $(\mathrm{r}=-0.41, \mathrm{p}<0.05)$ between ICPPA and CPP confirming the hypothesis that higher CPP results in a lower ICPPA when cerebral autoregulation is intact

moderate disability/good recovery than in the category of severe disability. With decreasing GCS, the ICPPA increased.

Head elevation and cerebral hemodynamics

The ICPPA is relatively easy to determine. So far, it was unclear whether or not there is a correlation between ICPPA and CPP during a change in head elevation. Provided that cerebral autoregulation is intact, the ICPPA reacts opposite to changes in CPP. With the knowledge of the negative correlation between ICPPA and CPP, the ICPPA may be used as a target value to aim at the lowest ICPPA in determining the upper body position with the highest CPP. In comparison of the values at positions of $0^{\circ}, 30^{\circ}$, and $60^{\circ}$,

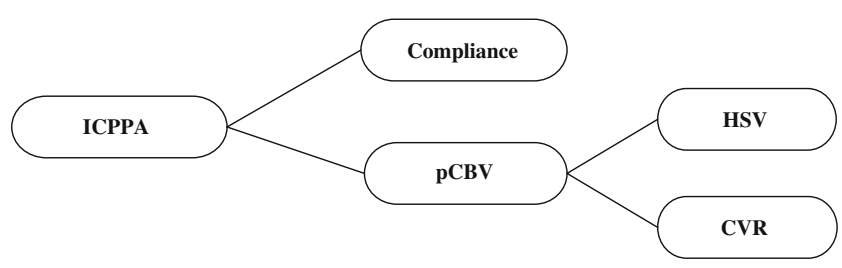

Fig. 6 Factors determining the ICPPA. The ICPPA depends on craniospinal compliance and pulsatile cerebral blood volume (pCBV). pCBV again depends on heart stroke volume (HSV) and CVR. Provided that compliance and cardiac parameters remain constant during change in body position, ICPPA reflects the change in CVR, which is a response to a change in CPP. A higher CPP leads to vasoconstriction and thus a lower ICPPA 


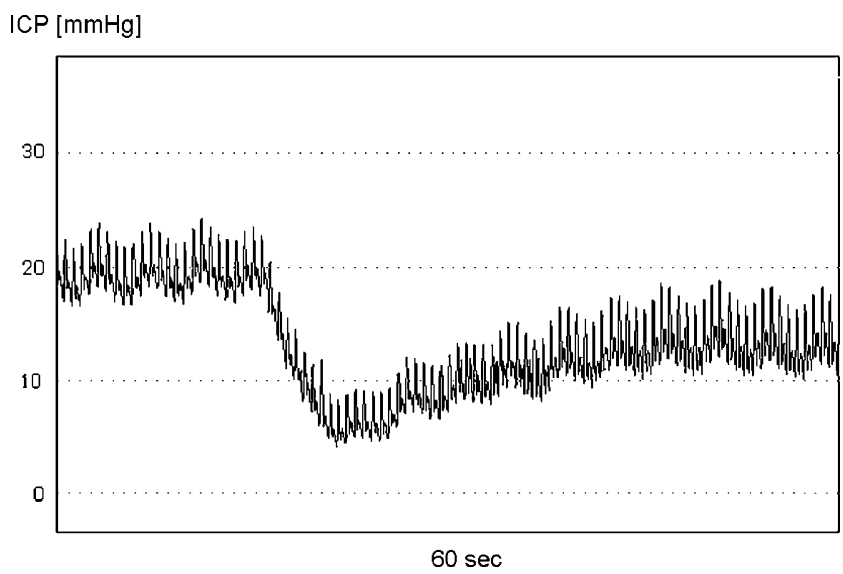

Fig. 7 Example of a head elevation from $0^{\circ}$ to $60^{\circ}$. Mean ICP decreases as the head is elevated. However, vasodilatation caused by a CPP decrease leads to a gradual increase of ICP mean value and more extensively to an increase in ICPPA. Note that after elevating the head from $0^{\circ}$ to $60^{\circ}$, the ICPPA is actually higher at a lower ICP mean than before head elevation, reflecting vasodilatation

we found the lowest ICPPA most often occurred at the $30^{\circ}$ position. However, 13 patients showed lower ICPPA values at $0^{\circ}$ position. The $30^{\circ}$ head-up position is often used intuitively, and it was shown to be associated with low ICP and improved cerebral oxygenation in several studies [13, $16,23,29,33,34,40,53]$. However, all these studies also showed a considerable individual variability in terms of the optimum level of head elevation. The ideal head position for patients with head injury has been debated in recent years. In critically ill patients with acute brain injury and associated intracranial hypertension, elevation of the head is clinically used to effect a reduction in the ICP $[2,23,40]$. A high ICP may lead to further brain damage by promoting ischemia, causing subsequent brain shift herniation.

Several investigators deal with the effects of head posture on cerebral hemodynamics. Durward et al. [13] found that head elevation of $15^{\circ}$ to $30^{\circ}$ was associated with a decrease in the ICP with maintenance of the CPP and cardiac output, while a head position of $60^{\circ}$ usually resulted in a decrease in MAP and therefore in CPP. We could confirm these findings using ICPPA analysis.

Rosner et al. [41] speculated that maximal CPP always occurred with the head in a horizontal position whether or not the ICP reached its maximum. Hence, they, and later Schwarz et al. [42], postulated that if adequate CPP is viewed as more desirable than an absolute level of ICP, then $0^{\circ}$ head elevation is the optimal position to achieve this goal. As mentioned earlier, this was true for 13 of our patients where ICPPA was lowest in the $0^{\circ}$ position.

The results of a study by Feldman et al. [16] suggested that head-injured patients with raised ICP should be positioned with the head elevated to $30^{\circ}$. This will produce a reduction of the ICP without a significant decrease in cerebral blood flow $(\mathrm{CBF})$ or $\mathrm{CPP}$ in the majority of measured patients. However, again there was considerable individual variability.

In comparison to the horizontal position, the head elevated to $30^{\circ}$ also reduces the risk for silent or smallvolume gastric reflux and the complications of pulmonary aspiration [52]. In a study with 22 head-injured patients, Meixensberger et al. [31] showed that moderate head elevation of 30 degrees reduces ICP without jeopardizing regional cerebral microcirculation as monitored using a polarographic ti- $\mathrm{pO}_{2}$ microcatheter.

$\mathrm{Ng}$ et al. [34] found that there is even no serious change in global cerebral oxygenation and regional cerebral oxygenation between $0^{\circ}$ and $30^{\circ}$ of head elevation and confirmed the absence of any adverse effect of $30^{\circ}$ head-up position.

Limitations of using ICPPA as a parameter for assessing CPP changes

Preserved cerebrovascular autoregulation is a requirement for using the ICPPA as a clinical parameter for assessing CPP. This essential mechanism keeps the CBF constant over a wide range of CPP $(50-150 \mathrm{mmHg})$ by triggering vasoconstriction or vasodilatation $[3,18-21,26,44,48,50$, 54]. Cerebral autoregulation can be understood as a self-defense mechanism against secondary ischemia, but also transmission of high blood pressure into the capillary bed. Impairment of autoregulation is found in a variety of diseases, such as head injury, ischemic stroke, and SAH [35]. In circumstances where autoregulation is impaired, changes in CPP or MAP may aggravate secondary brain injury, and this was found to be associated with poor outcome $[15,25,36]$. Up to now, it is still unclear whether disturbances in autoregulation are generalized, regional, or perifocal. It is likely that all these disturbances may occur in neurosurgical critical care patients. Thus, inappropriate volume loading or periods of spontaneous or induced hypertension may aggravate brain edema. However, awareness of autoregulation as an important protective mechanism for patients with $\mathrm{SAH}$ and traumatic brain injury increases [10, 11, 25, 46, 47].

Assessment of autoregulation may help identify patients and situations associated with a high risk of secondary ischemia. Many different static or dynamic tests have been proposed for the evaluation of cerebrovascular autoregulation. Aaslid et al. [1] developed a test for clinical application using TCD to record cerebral blood flow velocity (TCD-FV) during a drop in blood pressure by deflation of leg cuffs. They found that intact autoregulatory responses are characterized by initial pressure-passive decreases in TCD-FV followed by returns to baseline within a few seconds.

Another clinical test of autoregulation was performed by Diehl et al. [12]. Deep breathing at a constant rate evokes 
sinusoidal oscillations in blood pressure at the respiratory frequency. These variations are transmitted to CBFV, and thereby a positive phase shift angle between $\mathrm{CBFV}$ and $\mathrm{ABP}$ oscillations occurs. This phase shift angle is significantly reduced in patients with exhausted autoregulation. This test can also be performed when a patient is intubated and artifically ventilated; however, it has not found clinical acceptance.

The transient hyperemic response test (TRHT) was first introduced by Giller et al. [17]. Later, Smiliewski et al. [45] refined it by using the transient hyperemic response ratio (THRR) [8]. For this index, the maximum increase of FV (determined by TCD) is divided by baseline values after release of the carotid compression. With some limitation, this test is suitable for regular clinical usage [45].

More recently, a less invasive method based on spontaneous changes in MAP has been introduced [11]. The indices of autoregulation are calculated as moving correlation coefficients between spontaneous slow changes in MAP and slow changes in systolic (systolic index; Sx) or mean (mean index; Mx) flow velocities (FV), which can be used as indicators of autoregulation $[11,37,46]$. The higher the FV, the more impaired the cerebral autoregulation [46]. The pressure reactivity index (PRx), described by Czosnyka et al. [10], measures the correlation between ABP and ICP waves and may reflect cerebral autoregulation in response to blood pressure changes. A negative PRx reflects intact cerebrovascular response, whereas a positive PRx reflects a passive nonreactive behavior of the vascular bed. Cerebral autoregulation is a complex mechanism that shows variability over time and is best monitored continuously as part of multimodal neuromonitoring systems [24, 38]. The PRx is probably the test that suits best for assessing autoregulation in the clinical routine in patients with ICP monitoring and ABP measurement.

\section{Conclusion}

Head elevation is an important part of the ICP and CPP therapy in neurointensive care. When searching for the patient-specific optimum upper body position, ICPPA may provide additional information. Providing that the cerebral autoregulation is intact, the lowest ICPPA of a patient corresponds to the individual upper body position with the highest CPP.

\section{References}

1. Aaslid R, Lindegaard KF, Sorteberg W, Nornes H (1989) Cerebral autoregulation dynamics in humans. Stroke 20:45-52

2. Abbushi W, Herkt G, Speckner E, Birk M (1980) Intracranial pressure - variations in brain-injured patients caused by PEEP- ventilation and lifted position of the upper part of the body. Anaesthesist 29:521-524

3. Agnoli A, Fieschi C, Bozzao L, Battistini N, Prencipe M (1968) Autoregulation of cerebral blood flow. Studies during drug-induced hypertension in normal subjects and in patients with cerebral vascular diseases. Circulation 38:800-812

4. Avezaat CJ, van Eijndhoven JH (1984) Cerebrospinal Fluid Pulse Pressure And Craniospinal Dynamics. A. Jongblood en Zoon, The Hague

5. Avezaat CJ, van Eijndhoven JH, Wyper DJ (1979) Cerebrospinal fluid pulse pressure and intracranial volume-pressure relationships. J Neurol Neurosurg Psychiatry 42:687-700

6. Avezaat C, van Eijndhoven JHM, deJong D, Moolenaar W (1976) A new method of monitoring intracranial volume/pressure relationship. In: Intracranial Pressure, Springer Berlin, pp 308-313

7. Bratton SL, Chestnut RM, Ghajar J, Connell Hammond FF, Harris OA, Hartl R, Manley GT, Nemecek A, Newell DW, Rosenthal G, Schouten J, Shutter L, Timmons SD, Ullman JS, Videtta W, Wilberger JE, Wright DW (2007) Guidelines for the management of severe traumatic brain injury. VII. Intracranial pressure monitoring technology. J Neurotrauma 24(Suppl 1):S45S54

8. Czosnyka M, Pickard J, Whitehouse H, Piechnik S (1992) The hyperaemic response to a transient reduction in cerebral perfusion pressure. A modelling study. Acta Neurochir (Wien ) 115:90-97

9. Czosnyka M, Pickard JD (2004) Monitoring and interpretation of intracranial pressure. J Neurol Neurosurg Psychiatry 75:813-821

10. Czosnyka M, Smielewski P, Kirkpatrick P, Laing RJ, Menon D, Pickard JD (1997) Continuous assessment of the cerebral vasomotor reactivity in head injury. Neurosurgery 41:11-17

11. Czosnyka M, Smielewski P, Kirkpatrick P, Menon DK, Pickard JD (1996) Monitoring of cerebral autoregulation in head-injured patients. Stroke 27:1829-1834

12. Diehl RR, Linden D, Lucke D, Berlit P (1995) Phase relationship between cerebral blood flow velocity and blood pressure. A clinical test of autoregulation. Stroke 26:1801-1804

13. Durward QJ, Amacher AL, Del Maestro RF, Sibbald WJ (1983) Cerebral and cardiovascular responses to changes in head elevation in patients with intracranial hypertension. J Neurosurg 59:938-944

14. Eide PK, Sorteberg W (2006) Intracranial pressure levels and single wave amplitudes, Glasgow Coma Score and Glasgow Outcome Score after subarachnoid haemorrhage. Acta Neurochir (Wien) 148:1267-1275

15. Enevoldsen EM, Jensen FT (1978) Autoregulation and CO2 responses of cerebral blood flow in patients with acute severe head injury. J Neurosurg 48:689-703

16. Feldman Z, Kanter MJ, Robertson CS, Contant CF, Hayes C, Sheinberg MA, Villareal CA, Narayan RK, Grossman RG (1992) Effect of head elevation on intracranial pressure, cerebral perfusion pressure, and cerebral blood flow in head-injured patients. J Neurosurg 76:207-211

17. Giller CA (1991) A bedside test for cerebral autoregulation using transcranial Doppler ultrasound. Acta Neurochir (Wien) 108:7-14

18. Haggendal E (1965) Blood flow autoregulation of the cerebral grey matter with comments on its mechanism. Acta Neurol Scand Suppl 14:104-110

19. Haggendal E, Johansson B (1965) Effects of arterial carbon dioxide tension and oxygen saturation on cerebral blood flow autoregulation in dogs. Acta Physiol Scand Suppl 258:27-53

20. Harper AM (1966) Autoregulation of cerebral blood flow: influence of the arterial blood pressure on the blood flow through the cerebral cortex. J Neurol Neurosurg Psychiatry 29:398-403

21. Harper AM, Lassen NA, MacKenzie ET, Rowan JO, Sengupta D, Strandgaard S (1973) Proceedings: The upper limit of 'autoregulation' of cerebral blood flow in the baboon. J Physiol 234:61P-62P 
22. Juul N, Morris GF, Marshall SB, Marshall LF (2000) Intracranial hypertension and cerebral perfusion pressure: influence on neurological deterioration and outcome in severe head injury. The executive committee of the international selfotel trial. J Neurosurg 92:1-6

23. Kenning JA, Toutant SM, Saunders RL (1981) Upright patient positioning in the management of intracranial hypertension. Surg Neurol 15:148-152

24. Kett-White R, Hutchinson PJ, Czosnyka M, Boniface S, Pickard JD, Kirkpatrick PJ (2002) Multi-modal monitoring of acute brain injury. Adv Tech Stand Neurosurg 27:87-134

25. Lang EW, Diehl RR, Mehdorn HM (2001) Cerebral autoregulation testing after aneurysmal subarachnoid hemorrhage: the phase relationship between arterial blood pressure and cerebral blood flow velocity. Crit Care Med 29:158-163

26. Lassen NA, Agnoli A (1972) The upper limit of autoregulation of cerebral blood flow-on the pathogenesis of hypertensive encepholopathy. Scand J Clin Lab Invest 30:113-116

27. Leech P, Miller JD (1974) Intracranial volume-pressure relationships during experimental brain compression in primates. 2. Effect of induced changes in systemic arterial pressure and cerebral blood flow. J Neurol Neurosurg Psychiatry 37:1099-1104

28. Leech P, Miller JD (1974) Intracranial volume-pressure relationships during experimental brain compression in primates. 3. Effect of mannitol and hyperventilation. J Neurol Neurosurg Psychiatry 37:1105-1111

29. Magnaes B (1976) Body position and cerebrospinal fluid pressure. Part 1: clinical studies on the effect of rapid postural changes. J Neurosurg 44:687-697

30. Marmarou A, Shulman K, LaMorgese J (1975) Compartmental analysis of compliance and outflow resistance of the cerebrospinal fluid system. J Neurosurg 43:523-534

31. Meixensberger J, Baunach S, Amschler J, Dings J, Roosen K (1997) Influence of body position on tissue-pO2, cerebral perfusion pressure and intracranial pressure in patients with acute brain injury. Neurol Res 19:249-253

32. Miller JD, Pickard JD (1974) Intracranial volume pressure studies in patients with head injury. Injury 5:265-268

33. Moraine JJ, Berre J, Melot C (2000) Is cerebral perfusion pressure a major determinant of cerebral blood flow during head elevation in comatose patients with severe intracranial lesions? J Neurosurg 92:606-614

34. Ng I, Lim J, Wong HB (2004) Effects of head posture on cerebral hemodynamics: its influences on intracranial pressure, cerebral perfusion pressure, and cerebral oxygenation. Neurosurgery 54:593-597

35. Panerai RB, White RP, Markus HS, Evans DH (1998) Grading of cerebral dynamic autoregulation from spontaneous fluctuations in arterial blood pressure. Stroke 29:2341-2346

36. Paulson OB, Strandgaard S, Edvinsson L (1990) Cerebral autoregulation. Cerebrovasc Brain Metab Rev 2:161-192

37. Piechnik SK, Yang X, Czosnyka M, Smielewski P, Fletcher SH, Jones AL, Pickard JD (1999) The continuous assessment of cerebrovascular reactivity: a validation of the method in healthy volunteers. Anesth Analg 89:944-949

38. Rasulo FA, Balestreri M, Matta B (2002) Assessment of cerebral pressure autoregulation. Curr Opin Anaesthesiol 15:483-488

39. Robertson CS, Valadka AB, Hannay HJ, Contant CF, Gopinath SP, Cormio M, Uzura M, Grossman RG (1999) Prevention of secondary ischemic insults after severe head injury. Crit Care Med 27:2086-2095

40. Ropper AH, O'Rourke D, Kennedy SK (1982) Head position, intracranial pressure, and compliance. Neurology 32:1288-1291
41. Rosner MJ, Coley IB (1986) Cerebral perfusion pressure, intracranial pressure, and head elevation. J Neurosurg 65:636-641

42. Schwarz S, Georgiadis D, Aschoff A, Schwab S (2002) Effects of body position on intracranial pressure and cerebral perfusion in patients with large hemispheric stroke. Stroke 33:497-501

43. Shapiro K, Marmarou A (1982) Clinical applications of the pressure-volume index in treatment of pediatric head injuries. $\mathrm{J}$ Neurosurg 56:819-825

44. Skinhoj E, Hoedt-Rasmussen K, Paulson OB, Lassen NA (1970) Regional cerebral blood flow and its autoregulation in patients with transient focal cerebral ischemic attacks. Neurology 20:485-493

45. Smielewski P, Czosnyka M, Kirkpatrick P, McEroy H, Rutkowska H, Pickard JD (1996) Assessment of cerebral autoregulation using carotid artery compression. Stroke 27:2197-2203

46. Soehle M, Czosnyka M, Pickard JD, Kirkpatrick PJ (2004) Continuous assessment of cerebral autoregulation in subarachnoid hemorrhage. Anesth Analg 98:1133-1139

47. Steiner LA, Czosnyka M, Piechnik SK, Smielewski P, Chatfield D, Menon DK, Pickard JD (2002) Continuous monitoring of cerebrovascular pressure reactivity allows determination of optimal cerebral perfusion pressure in patients with traumatic brain injury. Crit Care Med 30:733-738

48. Strandgaard S, MacKenzie ET, Sengupta D, Rowan JO, Lassen NA, Harper AM (1974) Upper limit of autoregulation of cerebral blood flow in the baboon. Circ Res 34:435-440

49. Sullivan HG, Miller JD, Griffith RL III, Becker DP (1978) CSF pressure-volume dynamics in neurosurgical patients: a preliminary evaluation in six patients. Surg Neurol 9:47-54

50. Symon L, Held K, Dorsch NW (1973) A study of regional autoregulation in the cerebral circulation to increased perfusion pressure in normocapnia and hypercapnia. Stroke 4:139-147

51. Tans JT, Poortvliet DC (1983) Intracranial volume-pressure relationship in man. Part 2: Clinical significance of the pressurevolume index. J Neurosurg 59:810-816

52. Torres A, Serra-Batlles J, Ros E, Piera C, de la Puig BJ, Cobos A, Lomena F, Rodriguez-Roisin R (1992) Pulmonary aspiration of gastric contents in patients receiving mechanical ventilation: the effect of body position. Ann Intern Med 116:540-543

53. Winkelman C (2000) Effect of backrest position on intracranial and cerebral perfusion pressures in traumatically brain-injured adults. Am J Crit Care 9:373-380

54. Yoshida K, Meyer JS, Sakamoto K, Handa J (1966) Autoregulation of cerebral blood flow. Electromagnetic flow measurements during acute hypertension in the monkey. Circ Res 19:726-738

\section{Comment}

Often simple things can make a big difference, as the authors of this well-written paper have shown. It does make sense that head elevation is beneficial for the patient after surgery as it is to a moderate extent during surgery to reduce ICP and venous oozing. ICP monitoring preferably with CSF drainage is another important means of following comatose patients' ICP and cerebral perfusion. It allows accurate and timely imaging to be performed in case of raised ICP followed by decompressive procedures when indicated if conservative therapy is not sufficient.

Mika Niemelä

Juha Hernesniemi

Helsinki, Finland 